\title{
Effects of exercise-based cardiac rehabilitation on heart rate variability and turbulence in patients with ST elevation myocardial infarction
}

\author{
İsmet Zengin $\odot$, Selma Arı๑, Hasan Arı॰, Mehmet Melek $\odot$ \\ Department of Cardiology, University of Health Sciences, Bursa Yüksek İhtisas Training and Research Hospital, Bursa, Turkey
}

\begin{abstract}
Objectives: The objective of this study was to evaluate the effect of the exercise-based cardiac rehabilitation (CR) on the heart rate variability (HRV) and turbulence (HRT) in patients with ST elevation myocardial infarction (STEMI) treated with the primary percutaneous coronary intervention (PCI).

Methods: One hundred one patients with STEMI, who underwent primary PCI were included in our study. Sixty-eight of these patients were randomized to the CR group and the remaining 33 patients to the control group. One month after the primary PCI, cardiac rehabilitation was performed in CR group with a cycle ergometer for 8 weeks (30 sessions). One month after STEMI, rhythm Holter monitorization was carried out in both groups for 48 hours. The rhythm Holter monitorization was repeated in cardiac rehabilitation group (CR group) after the cardiac rehabilitation again for 48 hours. HRV was evaluated according to time and frequency domains; HRT was evaluated with the turbulence onset and turbulence slope parameters obtained from the Holter recordings.

Results: Baseline characteristics and baseline HRV and HRT parameters were comparable between CR group and control group. In CR group, there was no statistically significant difference between the HRV and HRT parameters, which were obtained before and after the cardiac rehabilitation. The subgroup analyses (left ventricular ejection fraction lower or higher than $40 \%$ ) showed that turbulence onset improved with the cardiac rehabilitation in the group with an ejection fraction lower than $40 \%$.

Conclusions: Our results showed that exercise-based cardiac rehabilitation did not affect HRV and HRT in patients whose left ventricular ejection fraction was mildly affected $(>40 \%)$ after the treatment with primary PCI. However, the cardiac rehabilitation provided an improvement of turbulence onset in patients with the low left ventricular ejection fraction.
\end{abstract}

Keywords: Cardiac rehabilitation, ST elevation myocardial infarction, heart rate variability, heart rate turbulence

T he cardiac rehabilitation (CR) can be defined as the whole of the activities, which are necessary for the patients with cardiovascular diseases to restore the premorbid physical, mental and social skills as quickly as possible [1]. Several studies documented the efficacy of the exercise-based CR after diffuse myocardial infarction (MI). The exercise improves concurrently the physical performance, muscle strength; dyspnea and angina symptoms and a comprehensive CR implementation are related to the improvement of 
the psychological and social functions, going back to work and biological risk factors.

It is well known that the balance between the sympathetic tonus and vagal tonus is changing in favor of sympathetic tonus after the MI. The CR decreases the risk of sudden death as a result of the increase in the fibrillation threshold depending on the increase in the vagal tonus [2]. The autonomous function disorders of the cardiac system have an important place in the pathophysiology of the malign arrhythmias and sudden cardiac death (SCD) [3]. It was reported that after the ischemia and infarction, the parasympathetic tonus decreases along with the decrease of the ventricular fibrillation (VF) threshold due to the increased catecholamines [4]. Heart rate variability (HRV) and heart rate turbulence (HRT) are tests related to the cardiac autonomous functions. HRV shows the effects of the parasympathetic and sympathetic systems on the heart rate. After a ventricular ectopic beat, the sinus rate first increases and then decreases. HRT is used to investigate this phenomenon. It is a reliable indicator of the baroreceptor sensitivity $[5,6]$. HRT is evaluated with these two parameters: Turbulence onset (TO) and the turbulence slope (TS). The European Society of Cardiology stated that HRV is a reliable indicator of the vagal activity and is an independent indicator of the total mortality [7]. Likewise, our objective was to evaluate the effect of the CR on the cardiac autonomous functions with the help of the HRV and HRT parameters in ST elevation myocardial infarction (STEMI) patients.

\section{METHODS}

\section{Patient Selection}

One hundred one consecutive patients, who had applied to the Bursa Yüksek İhtisas Training and Research Hospital and had been admitted with the diagnosis of STEMI in 2014, were included in the study. Their ages ranged between 35 and 85 years and all had undergone primary PCI. In 68 of these patients, CR was performed at least one month after the primary PCI. The remaining 33 patients formed the control group. Patients, who had serious valve disease, had an age over 85 years, respiratory function disorders, decompensated heart failure, uncontrolled hypertension (HT), diabetes mellitus (DM), orthopedic disability, previous cerebrovascular disease and did not accept the CR program for different reasons, were excluded from the study. Patients, who did not have a sinus rhythm and had a pacemaker rhythm, were also excluded from the study. The findings in the anamnesis and physical examination, risk factors related to atherosclerosis, demographic characteristics, maximum troponin and CK-MB levels at admission, lipid parameters were recorded. Echocardiographic examination was performed and the obtained data were evaluated according to the guideline of the American Echocardiography Society with the standard technique and the $3.5 \mathrm{MHz}$ phaseadjusted transducer GE Vivid 7 pro device (General Electric Company, Connecticut, USA).

\section{Cardiac Rehabilitation Procedure}

The patients, who had STEMI and underwent PCI were included in the 8-week CR program after one month from the intervention. CR was performed with a cycle ergometer for 8 weeks, according to the targeted Watt level and heart rate. The average numbers of sessions per week were 4 and each session lasted approximately 30 minutes ( 5 minutes warm-up, 20 minutes aerobic exercise, which increased the heart rate up to $70-85 \%$ and 5 minutes cool down).

\section{Rhythm Holter Analysis}

In both groups, at least one month after STEMI, rhythm Holter monitorization (ELA Spiderview Digital Recorder, Ela Medical, Paris 2007) was carried out for 48 hours. The rhythm Holter monitorization was repeated for 48 hours in patients, who completed the rehabilitation. The records of the Holter monitorization were uploaded to a computer and analyzed with the Holter software package (ELA Medical SYNESCOPE MultiChannel- Multiday Version 3.10). Initially, the artifacts at the "template" tab, normal and ventricular beats were determined. Then, the average maximum, minimum and mean heart rates were calculated as the mean of the 48-hour recordings. The HRV values were evaluated with the following parameters: Time domain; PNN50 (The division of the NN50 counts to the total NN count), RMSSD (root-mean-square differences of successive $\mathrm{NN}$ intervals), ASDNN (mean of the standard deviation in all 5-minute segments), SDNN (standard deviation of all $\mathrm{NN}$ intervals). The frequency domain 
Table 1. The demographic characteristics, laboratory parameters, lesion and intervention features

\begin{tabular}{|c|c|c|c|}
\hline & $\begin{array}{c}\text { CR Group } \\
(\mathrm{n}=68)\end{array}$ & $\begin{array}{c}\text { Control Group } \\
(\mathbf{n}=\mathbf{3 3})\end{array}$ & $p$ value \\
\hline Age (years) & $58.23 \pm 9.69$ & $55.48 \pm 9.99$ & 0.21 \\
\hline Gender & & & 0.77 \\
\hline Male, n (\%) & $54(79.4)$ & $27(81.8)$ & \\
\hline Female, n (\%) & $14(20.6)$ & $6(18.2)$ & \\
\hline Diabetes mellitus, n (\%) & $13(19.4)$ & 7 (21.9) & 0.77 \\
\hline Hypertension, $\mathrm{n}(\%)$ & $24(35.8)$ & $6(18.8)$ & 0.08 \\
\hline Hyperlipidemia, n (\%) & $16(23.9)$ & $10(31.3)$ & 0.43 \\
\hline Smoking, n (\%) & $31(46.3)$ & $21(70)$ & 0.03 \\
\hline Previous PCI n (\%) & $7(10.4)$ & $4(12.1)$ & 0.80 \\
\hline LVEF (\%) & $42.13 \pm 11.07$ & $42.12 \pm 9.13$ & 0.90 \\
\hline End-diastole diameter (mm) & $47.00 \pm 3.58$ & $47.06 \pm 4.47$ & 0.84 \\
\hline End-systole diameter (mm) & $32.03 \pm 4.46$ & $32.19 \pm 4.97$ & 0.67 \\
\hline Systolic blood pressure (mmHg) & $115.80 \pm 9.79$ & $111.77 \pm 13.81$ & 0.10 \\
\hline Diastolic blood pressure $(\mathrm{mmHg})$ & $71.02 \pm 7.94$ & $69.03 \pm 8.4$ & 0.28 \\
\hline Mean heart rate (beat/min) & $66.23 \pm 8.04$ & $69.69 \pm 10.31$ & 0.069 \\
\hline $\mathrm{WBC}\left(\times 10^{3}\right)$ & $9.61 \pm 2.80$ & $9.5 \pm 2.34$ & 0.97 \\
\hline Hemoglobin (g/dl) & $13.10 \pm 1.52$ & $13.79 \pm 1.26$ & 0.03 \\
\hline Platelet count $\left(\times 10^{3}\right)$ & $256.70 \pm 83.85$ & $230.41 \pm 42.69$ & 0.27 \\
\hline Urea (mg/dl) & $15.77 \pm 4.51$ & $15.51 \pm 5.43$ & 0.49 \\
\hline Creatinine (mg/dl) & $0.8 \pm 0.17$ & $0.79 \pm 0.18$ & 0.55 \\
\hline Total Cholesterol (mg/dl) & $179.96 \pm 47.41$ & $182.48 \pm 41.33$ & 0.51 \\
\hline LDL-C (mg/dl) & $120.36 \pm 44.61$ & $117.84 \pm 35.26$ & 0.70 \\
\hline HDL-C (mg/dl) & $35.60 \pm 10.54$ & $31.38 \pm 8.6$ & 0.08 \\
\hline Triglycerides (mg/dl) & $114.95 \pm 94.11$ & $167.48 \pm 163.46$ & 0.056 \\
\hline Sodium (mEq/L) & $140.07 \pm 2.57$ & $140.64 \pm 2.25$ & 0.19 \\
\hline Potassium $(\mathrm{mEq} / \mathrm{L})$ & $4.43 \pm 0.39$ & $4.27 \pm 0.45$ & 0.10 \\
\hline Troponin max (ng/mL) & $91.99 \pm 97.62$ & $89.34 \pm 87.76$ & 0.71 \\
\hline CK-MB max (ng/mL) & $180.02 \pm 163.67$ & $198.35 \pm 140.27$ & 0.27 \\
\hline Time to the start of rehabilitation (days) & $62.21 \pm 29.33$ & - & \\
\hline \multicolumn{4}{|l|}{ Drugs } \\
\hline ASA, n (\%) & $68(100)$ & $33(100)$ & 1.0 \\
\hline Klopidogrel, n (\%) & $42(61.8)$ & $17(51.5)$ & 0.32 \\
\hline Ticagrelor, $\mathrm{n}(\%)$ & $26(38.2)$ & $16(48.5)$ & 0.32 \\
\hline Beta-blocker, n (\%) & $66(98.5)$ & $33(100)$ & 0.99 \\
\hline ACE-I, n (\%) & $60(89.6)$ & $30(90.9)$ & 0.83 \\
\hline $\mathrm{ARB}, \mathrm{n}(\%)$ & $6(9.1)$ & $2(6.1)$ & 0.60 \\
\hline Statin, n (\%) & $68(100)$ & $32(97)$ & 0.99 \\
\hline Nitrate, n (\%) & $7(10.6)$ & $2(6.1)$ & 0.45 \\
\hline Diuretics, $\mathrm{n}(\%)$ & $6(9.1)$ & $2(6.1)$ & 0.60 \\
\hline Spironolactone, n (\%) & $27(40.9)$ & $9(27.3)$ & 0.18 \\
\hline Myocardial infarction region & & & 0.66 \\
\hline Anterior, $\mathrm{n}(\%)$ & $34(50)$ & $15(45.5)$ & \\
\hline Inferior, $\mathrm{n}(\%)$ & $34(50)$ & $18(54.5)$ & \\
\hline Location of the responsible lesion & & & 0.77 \\
\hline LAD, n (\%) & $35(53)$ & $15(45.5)$ & \\
\hline $\mathrm{CX}, \mathrm{n}(\%)$ & $12(18.2)$ & $7(21.2)$ & \\
\hline RCA, n (\%) & $19(28.8)$ & $11(33.3)$ & \\
\hline Intervention & & & 0.55 \\
\hline Stent, n (\%) & $66(97)$ & $33(100)$ & \\
\hline PTCA, n $(\%)$ & $2(3)$ & - & \\
\hline Duration of pain (min) & $205.56 \pm 202.61$ & $142.96 \pm 133.36$ & 0.11 \\
\hline Door-to-balloon time (min) & $23.46 \pm 11.60$ & $22.16 \pm 10.72$ & 0.60 \\
\hline
\end{tabular}

Data are shown as mean \pm standard deviation or number $(\%)$. ACEI $=$ angiotensin-converting enzyme inhibitors, ARB $=$ angiotensin receptor blockers, ASA = acetylsalicylic acid, $\mathrm{CKMB}=$ creatinine kinase $\mathrm{MB}$ isoenzyme, $\mathrm{Cx}=$ circumflex artery, HDL-C $=$ high density lipoprotein cholesterol, LAD = left anterior descending artery, LDL-C = low density lipoprotein cholesterol, LVEF $=$ left ventricular ejection fraction, $\mathrm{PCI}=$ percutaneous coronary intervention, $\mathrm{PTCA}=$ percutaneous transluminal coronary angioplasty, $\mathrm{RCA}=$ right coronary artery, $\mathrm{WBC}=$ white blood cell 
HRV parameters were determined in 5 different band intervals: HF (0.15-0.4 Hz), VLF (0.0-0.04 Hz), LF (0.04-0.15 Hz), total power (0.0-2.0) and LF/HF ratio. For the evaluation of the relative changes in the frequency field, $\mathrm{HF}$ power $\mathrm{HFnu}=100 \times \mathrm{HF}$ power/totalpower), normalized LF power $(\mathrm{LFnu}=100 \times \mathrm{LF}$ power/total power $)$ and low/high frequency power ratio $(\mathrm{LF} / \mathrm{HF}$ ratio $=\mathrm{LF}$ power $/ \mathrm{HF}$ power) were calculated. The TO and TS values (HRT parameters) were automatically calculated with the help of the Holter software package (HRT View Version 0.60-0,1 Munich, Germany) and ventricular premature beats, which provided the conformity criteria for the HRT measurement. The values less than $0 \%$ were accepted for the TO and the values more than $2.5 \mathrm{msec} / \mathrm{RR}$ were accepted for the TS [8]. Turbulence loss was accepted as the increase in TO and decrease in TS.

\section{Statistical Analysis}

SPSS software package (IBM SPSS Statistics Version 22) was used for the statistical analysis. The continuous variables were expressed in mean \pm standard deviation; categorical variables were expressed in percentages. The normal distribution characteristics of the continuous variables were checked with the Shapiro-Wilk normality test.
Independent-samples t-test and Mann-Whitney U test were used for the comparison of the parametric data and Chi-square test and the Fisher's exact test were used for the comparison of the categorical variables. The analysis of the repeated measurements (before and after the rehabilitation) was performed with the Wilcoxon signed-rank test. For all analysis, $p<0.05$ was considered as statistically significant.

\section{RESULTS}

The evaluation of the demographic characteristics and the laboratory analysis of the patients showed that the smoking rate was significantly higher in the control group $(p=0.03)$. The hemoglobin value was also significantly higher in the control group ( $p=$ $0.03)$. The biochemical parameters were comparable in both groups. There was no difference between the groups regarding the systolic and diastolic blood pressure and mean heart rate. The use of the medication was also comparable between the groups (Table 1).

There was also no difference between the rehabilitation group and the control group in respect of the MI area, treatment strategies and duration of pain (Table 1).

Table 2. 48-hour Holter findings in the rehabilitation and control groups

\begin{tabular}{|c|c|c|c|}
\hline & $\begin{array}{l}\text { CR Group } \\
(n=68)\end{array}$ & $\begin{array}{l}\text { Control Group } \\
\qquad(\mathbf{n}=\mathbf{3 3})\end{array}$ & $p$ value \\
\hline Mean HR (beat/min) & $66.23 \pm 8.04$ & $69.69 \pm 10.31$ & 0.06 \\
\hline Ventricular extrasystole & $624.05 \pm 1841.97$ & $129.78 \pm 252.40$ & 0.35 \\
\hline QT interval (msec) & $415.93 \pm 32.35$ & $401.93 \pm 29.06$ & 0.03 \\
\hline VT & & & 0.055 \\
\hline Yes, n (\%) & $11(16.2)$ & $1(3)$ & \\
\hline No, n $(\%)$ & $57(83.8)$ & $32(97)$ & \\
\hline SVT & & & 0.26 \\
\hline Yes, n (\%) & $25(36.8)$ & $16(48.5)$ & \\
\hline No, n $(\%)$ & $43(63.2)$ & $17(51.5)$ & \\
\hline
\end{tabular}

Data are shown as mean \pm standard deviation or number $(\%) . \mathrm{HR}=$ heart rate, $\mathrm{SVT}=$ supraventricular tachycardia, $\mathrm{VT}=$ ventricular tachycardia 
Table 3. HRV and HRT parameters obtained from the Holter recordings before the rehabilitation

\begin{tabular}{ccc} 
CR Group & Control Group & $p$ value \\
$(\mathrm{n}=68)$ & $(\mathrm{n}=33)$ & \\
\hline
\end{tabular}

\begin{tabular}{|cccc}
\hline HRV frequency domain analysis & & & \\
\hline TP $\left(\mathrm{msec}^{2}\right)$ & $7133.66 \pm 12572.95$ & $4037.30 \pm 7005.60$ & 0.41 \\
\hline LF $\left(\mathrm{msec}^{2}\right)$ & $1964.19 \pm 4000.70$ & $989.63 \pm 2129.09$ & 0.74 \\
\hline LF (nu) & $20.99 \pm 7.92$ & $21.20 \pm 6.46$ & 0.58 \\
\hline HF (msec $\left.{ }^{2}\right)$ & $1734.29 \pm 4235.26$ & $874.27 \pm 3252.12$ & 0.92 \\
\hline HF (nu) & $12.19 \pm 11.66$ & $11.84 \pm 9.71$ & 0.55 \\
\hline LF/HF ratio & $2.94 \pm 2.12$ & $2.67 \pm 1.68$ & 0.67 \\
\hline HRV time domain analysis & & & \\
\hline SDNN (msec) & $103.74 \pm 35.08$ & $99.76 \pm 33.33$ & 0.77 \\
\hline ASDNN (msec) & $71.80 \pm 51.89$ & $58.88 \pm 39.15$ & 0.45 \\
\hline RMSSD (msec) & $70.81 \pm 87.68$ & $52.82 \pm 67.10$ & 0.72 \\
\hline pNN50 (\%) & $9.22 \pm 10.85$ & $8.62 \pm 8.77$ & 0.85 \\
\hline
\end{tabular}

HRT parameters

\begin{tabular}{cccc} 
TO & $-0.0089 \pm 0.027$ & $-0.0027 \pm 0.031$ & 0.24 \\
TS & $9.26 \pm 8.13$ & $7.30 \pm 9.16$ & 0.17 \\
\hline
\end{tabular}

Data are shown as mean \pm standard deviation. $\mathrm{CR}=$ cardiac rehabilitation, $\mathrm{HR}=$ heart rate, $\mathrm{HRV}=$ heart rate variability, $\mathrm{HRT}=$ heart rate turbulence, $\mathrm{TO}=$ turbulence onset, $\mathrm{TS}=$ turbulence slope

There was no significant difference between the groups considering the main findings of the 48-hour Holter monitorization. There was no significant difference between the groups regarding the ventricular extrasystole count, the presence of the supraventricular and ventricular tachycardia. The QTinterval was $415 \pm 32 \mathrm{msec}$ and $401 \pm 29 \mathrm{msec}$ in the rehabilitation and control groups respectively. The QTinterval was significantly longer in the rehabilitation group ( $p=0.03$ ) (Table 2).

There was no difference between the pre-rehabilitation frequency domain analysis of the basal HRV parameters (TP, LF, LFnu, HF, HFnu, LF /HF) and time domain parameters (SDNN, ASDNN, RMSSD, pNN50). HRT parameters (TO and TS) were comparable in both groups (Table 3). In the rehabilitation group, there was no significant difference between HRV and HRT parameters before and after the rehabilitation (Table 4).

The analysis of the subgroup consisting of the patients with a left ventricule ejection fraction below than $40 \%$ showed that there was no significant difference between the HRV parameters before and after the rehabilitation. Regarding the HRT parameters; there was no significant difference before and after the rehabilitation for TS, but TO parameter significantly improve with CR (before the rehabilitation: -0.00014 \pm 0.021 , after the rehabilitation: $-0.0051 \pm 0.029, p=$ 0.04). (Table 5) (Fig. 1).

\section{DISCUSSION}

In our study, we found that the 8-week CR program, which STEMI patients underwent at least 
Table 4. HRV and HRT parameters in the rehabilitation group before and after the rehabilitation

\begin{tabular}{|c|c|c|c|}
\hline & $\begin{array}{l}\text { Before Rehabilitation } \\
\qquad(\mathrm{n}=68)\end{array}$ & $\begin{array}{l}\text { After Rehabilitation } \\
\qquad(\mathrm{n}=68)\end{array}$ & $p$ value \\
\hline HR (bpm) & $66.3 \pm 8.09$ & $66.9 \pm 7.50$ & 0.52 \\
\hline \multicolumn{4}{|c|}{ HRV frequency domain analysis } \\
\hline $\mathrm{TP}\left(\mathrm{msec}^{2}\right)$ & $7133.6 \pm 1257.8$ & $5183.0 \pm 1220.8$ & 0.88 \\
\hline $\mathrm{LF}\left(\mathrm{msec}^{2}\right)$ & $1964.1 \pm 400.0$ & $1376.4 \pm 411.7$ & 0.84 \\
\hline LF (nu) & $20.9 \pm 21.7$ & $21.7 \pm 8.0$ & 0.28 \\
\hline $\mathrm{HF}\left(\mathrm{msec}^{2}\right)$ & $1734.2 \pm 423.5$ & $1139.0 \pm 511.4$ & 0.82 \\
\hline $\mathrm{HF}(\mathrm{nu})$ & $12.1 \pm 11.6$ & $11.0 \pm 9.4$ & 0.87 \\
\hline $\mathrm{LF} / \mathrm{HF}$ ratio & $2.9 \pm 2.1$ & $3.2 \pm 2.4$ & 0.51 \\
\hline \multicolumn{4}{|l|}{ HRV time domain analysis } \\
\hline SDNN (msec) & $103.7 \pm 35.0$ & $102.7 \pm 28.1$ & 0.69 \\
\hline ASDNN (msec) & $71.8 \pm 51.8$ & $63.5 \pm 28.9$ & 0.95 \\
\hline RMSSD (msec) & $70.8 \pm 8.7$ & $52.9 \pm 5.6$ & 0.63 \\
\hline pNN50 (\%) & $9.2 \pm 8.1$ & $8.0 \pm 7.2$ & 0.96 \\
\hline \multicolumn{4}{|l|}{ HRT parameters } \\
\hline TO $(\%)$ & $-0.0089 \pm 0.002$ & $-0.0077 \pm 0.002$ & 0.72 \\
\hline TS (msec/RR) & $9.6 \pm 8.3$ & $7.3 \pm 6.4$ & 0.26 \\
\hline
\end{tabular}

one month after PCI, had no significant effect on the HRV and HRT parameters. The subgroup analysis showed that CR did not provide any significant change in HRV and HRT parameters in patients, who had a normal or mildly affected LVEF (LVEF $>40 \%$ ). On the other hand, we determined a significantly positive effect in TO for patients with an LVEF lower than $40 \%$. Our study is the first study in the literature, which is focused on the HRT parameters before and after CR in post-STEMI patients.

Most of the meta-analyses, which focused on the effects of CR on the cardiac mortality in acute MI patients, were conducted before the introduction of the modern revascularization techniques like the thrombolytic treatment and primary PCI. Hereby, it might come to mind whether the effects of CR on the mortality were still in place after the introduction of the modern revascularization techniques. Although, it was shown in a few studies that mortality was decreased, the lack of randomized and controlled studies focused on this topic should be taken into consideration. Goel et al. [9] has evaluated a retrospective study (published 2011) focused on a large patient population $(\mathrm{n}=2395)$, who underwent PCI between 1994 and 2008. In conclusion, it was determined that $\mathrm{CR}$ decreased significantly all-cause and cardiac mortalities after PCI [9]. In a metaanalysis, which was conducted with the support of the Cochrane Collaboration and published in 2001 and revised in 2005, 51 studies comprising 8440 patients 

Table 5. HRV and HRT findings in patients with $\mathrm{LVEF}<40 \%$ before and after the
rehabilitation

$\begin{array}{ccc}\begin{array}{c}\text { Before Rehabilitation } \\ (n=24)\end{array} & \begin{array}{c}\text { After Rehabilitation } \\ (n=24)\end{array} & p \text { value } \\ & & \end{array}$

HRV frequency domain analysis

\begin{tabular}{|cccc|}
\hline HR $(\mathrm{bpm})$ & $67.62 \pm 9.05$ & $68.42 \pm 7.58$ & 0.83 \\
\hline TP $\left(\mathrm{msec}^{2}\right)$ & $8628.11 \pm 15424.91$ & $7926.88 \pm 18159.08$ & 0.71 \\
\hline LF $\left(\mathrm{msec}^{2}\right)$ & $2436.55 \pm 4759.98$ & $2314.64 \pm 6051.47$ & 0.87 \\
\hline LF (nu) & $22.57 \pm 8.38$ & $23.52 \pm 8.62$ & 0.67 \\
\hline HF (msec $\left.{ }^{2}\right)$ & $2337.55 \pm 5007.81$ & $2478.55 \pm 7741.08$ & 0.82 \\
\hline HF (nu) & $15.30 \pm 12.24$ & $15.76 \pm 11.95$ & 0.50 \\
\hline LF/HF ratio & $2.39 \pm 1.54$ & $2.31 \pm 1.54$ & 0.91 \\
\hline HRV time domain analysis & & & \\
\hline SDNN (msec) & $104.78 \pm 35.33$ & $98.42 \pm 32.18$ & 0.12 \\
\hline ASDNN (msec) & $82.95 \pm 60.70$ & $72.10 \pm 42.74$ & 0.97 \\
\hline RMSSD (msec) & $48.64 \pm 42.29$ & $58.00 \pm 39.40$ & 0.11 \\
\hline pNN50 (\%) & $9.84 \pm 13.08$ & $8.53 \pm 6.63$ & 0.95 \\
\hline HRT parameters & & & \\
\hline TO (\%) & $-0.00014 \pm 0.021$ & $-0.0051 \pm 0.029$ & 0.04 \\
\hline TS (msec/RR) & $6.12 \pm 5.18$ & $5.08 \pm 5.08$ & 0.50 \\
\hline
\end{tabular}

Data are shown as mean \pm standard deviation. $\mathrm{CR}=$ cardiac rehabilitation, $\mathrm{HR}=$ heart rate, $\mathrm{HRV}=$ heart rate variability, $\mathrm{HRT}=$ heart rate turbulence, $\mathrm{TO}=$ turbulence onset, $\mathrm{TS}=$ turbulence slope

were systematically investigated [2]. In patients, who underwent cardiac rehabilitation, all-cause and cardiac mortalities decreased $27 \%$ and $31 \%$ respectively. There was also a $19 \%$ decrease in combined events (non-fatal MI, CABS, PTCA) [2].

The cardiac autonomous functions are impaired in MI patients and this impairment is correlated with the mortality and morbidity. Kleiger et al. [10] investigated HRV parameters with 24-hour Holter monitorization after $11 \pm 3$ days from the acute event in 808 patients. They determined a 2.4 -fold increase in the all-cause mortality during the 31-month followup in the group with SDNN $>50$ msec compared to the $\mathrm{SDNN}<50 \mathrm{msec}[10]$.

In a randomized and controlled study conducted by Oliveira et al. [11] and published in 2014, the effects of 8-week exercise-based CR on the cardiac autonomous functions were investigated in the MI patients. The HRV parameters were measured after this exercise program and no difference was detected between the exercise and control group regarding the HRV parameters. Only the VO2 peak level was significantly increased in the exercise group [11]. As the LVEF level was $>50 \%$ in this study, we assumed that the PCI implementation was efficient. This study was conducted a short time ago when the revascularization techniques and pharmacological agents were widely used and its results are consistent with our study.

The data related to the MI patients, who 


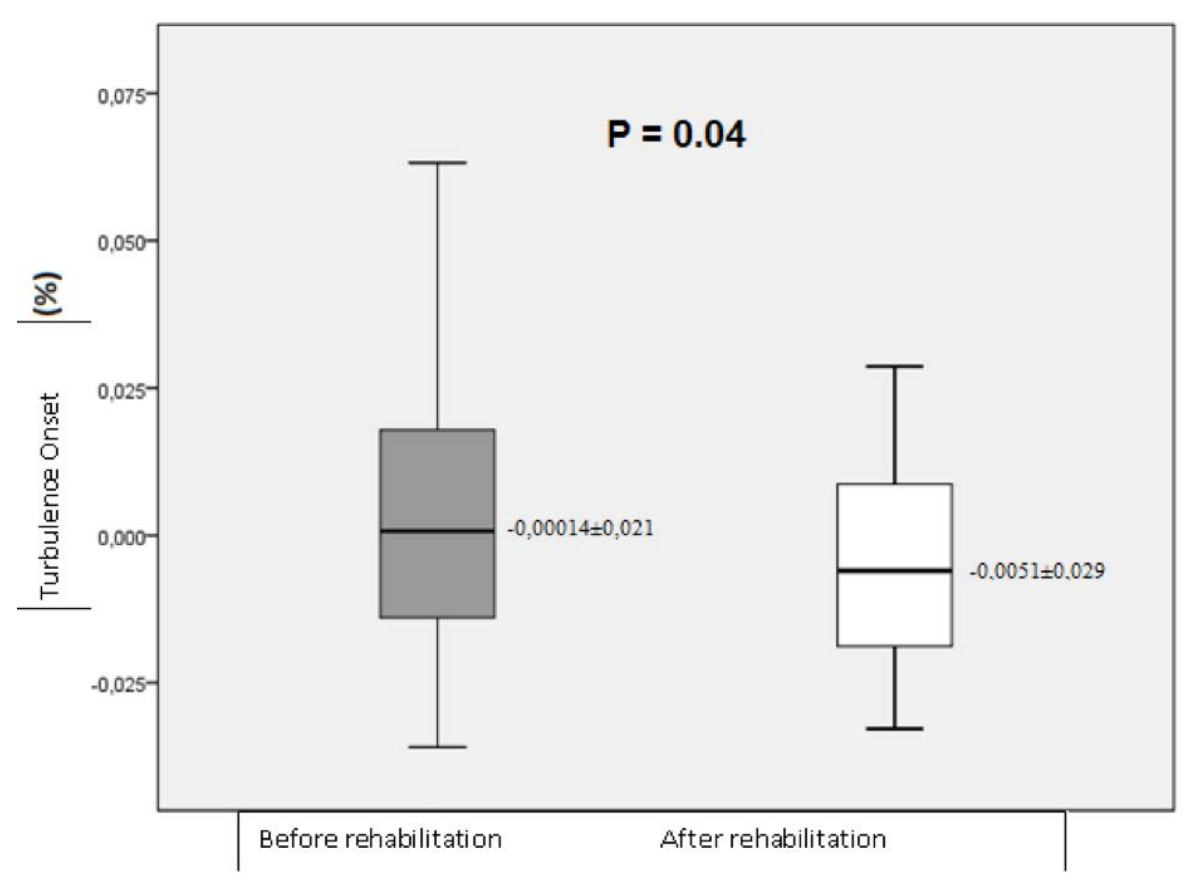

Fig. 1. Turbulence onset value in patients with $\mathrm{LVEF}<\mathbf{4 0 \%}$ before and after the rehabilitation.

underwent $\mathrm{CR}$, were based on the studies conducted 30 years ago. At that time, efficient revascularization techniques were not introduced yet and the use of several anti-platelet and anti-ischemic agents and the statin derivatives was not prevalent. Therefore, the cardiac damage was more severe and the survival rate was relatively lower. This fact brought along the questioning of the benefits of CR, which was effective at that time. In other words, the faster the treatment and the better the revascularization, the milder is the cardiac damage and consequently the benefit of CR is not much different from its benefit in the healthy population. In our study, our findings - no significant difference between the pre- and post-rehabilitation HRV and HRT values in the control group - confirm these results.

In our study, all patients were diagnosed with STEMI and underwent PCI. Other patients with acute coronary syndrome (ACS) were excluded from the study. Therefore, we can suggest that the study group was balanced and homogeneous. Studies related to the exercise program contained certain differences. In our study, we implemented an 8-week exercise program, which consisted of approx. 30-minute 4 sessions per week. The targeted heart rate was $70-85 \%$ of the resting heart rate. We did not detect any difference between the rehabilitation and control group regarding the HRV parameters. There was also no difference between the HRV parameters before and after the rehabilitation. These findings might be related to the revascularization at the early stage, minimally valve damage and drug treatment. Probably, the short doorto-balloon time and high rate of the compliance to the drug treatment prevented the deterioration of the cardiac autonomous functions and improved the impaired functions at the early stage. It is well known that post-MI acute sudden death rate is particularly high in the first month. In our study, the rehabilitation was started at least one month after the acute MI (mean time: $62 \pm 29$ days). Prior to the rehabilitation program, Holter monitorization was carried out for the evaluation of the baseline HRV and HRT parameters. Regarding the control group, 48-hour rhythm Holter monitorization was performed at least one month after the acute MI (mean: $86 \pm 57$ days). In our study, as it was mostly within the normal limits in both groups and there was no significant difference between the groups regarding the HRV and HRT parameters, we believe that these may be related to the study design, in which the measurements were not done in the first month, which is period with the highest level of the risks of ACD and the cardiac autonomous dysfunction.

The relatively limited cardiac damage may decrease the efficacy of the exercise-based CR and 
consequently, no difference in HRV and HRT parameters was detected after CR. The baseline values of the HRV parameters were higher in our study compared to other studies and were mostly within normal limits. These findings might be explained by the early and effective revascularization and the following preservation of the cardiac autonomous functions and with the normal HRV and HRT parameters comparable to the normal population. In addition, like the abovementioned study, the compliance to the treatment, use of the beta-blockers and ACE-inhibitors [12, 13], which particularly improve the cardiac autonomous functions, during the study and high tolerance of the drugs, might be related to this finding.

One of the subgroup analyses in the study ATRAMI (Autonomic Tone and Reflexes After Myocardial Infarction) showed that the patency of the artery responsible for the MI, was the major determinant in the post-MI baroreceptor response in the patient population, who underwent coronary angiography [14]. The post-MI baroreceptor activity and cardiac autonomous functions declined acutely. Nevertheless, it was demonstrated that the HRT parameters, which were one of the indicators of the cardiac autonomous functions, improved after the reperfusion [15]. This may be explained by the limited impact on the autonomous functions and faster improvement of them along with the corresponding HRT parameters as a result of the revascularization at the early stage with modern techniques. According to the findings of our study, CR was carried out on patients, who had mildly affected HRV and HRT parameters with levels similar to the normal population. This may be the reason that the postrehabilitation levels of these parameters did not change compared to the pre-rehabilitation levels.

HRT is usually abnormal in patients with heart failure. It was determined that TS below $2.5 \mathrm{~m} / \mathrm{sec}$ was related to the risk of the cardiac complications in patients with heart failure $(\mathrm{EF}<35 \%)$ [16]. In our study, in the subgroup analyses, we detected a significant difference between the TO values before and after the rehabilitation in patients with an LVEF below $40 \%$.

Therefore, it may be suggested that the patients, who had delayed revascularization and treatment and consequently increased cardiac damage followed by decreased SVEF, had a distinct clinical condition. It may be also suggested that $\mathrm{CR}$ is more effective in decreasing the mortality in patients with an LVEF lower than $40 \%$. However, further studies are needed for the confirmation.

\section{Limitations}

One of the limitations of our study is the lack of the 48-hour rhythm Holter monitorization in both rehabilitation and control groups within the same time. This may have caused some heterogeneity in HRV and HRT values. The HRV and HRT parameters were obtained from the rhythm Holter recordings during the routine daily activities. The evaluation of the Holter recordings during the exercise may present different results.

\section{CONCLUSION}

We did not determine any significant difference between the HRV and HRT parameters before and after the rehabilitation, in patients with STEMI who was treated with primary PCI. However, there was a significant and positive difference in TO parameter in patients with a left ventricular ejection fraction less than $40 \%$.

\section{Conflict of interest}

The authors disclosed no conflict of interest during the preparation or publication of this manuscript.

\section{Financing}

The authors disclosed that they did not receive any grant during conduction or writing of this study.

\section{REFERENCES}

1. Goble AJ, Worcester MUC. Best practice guidelines for cardiac rehabilitation and secondary prevention. Heart Research Center. Melbourne, on behalf of Department of Human Services Victoria; Australia, 1999. www.health.vic.gov.au.

2. Arat N. Akut Koroner Sendrom ve Perkütan Koroner Girişim Uygulanan Hastalarda Kardiyak Rehabilitasyon. In: Uzun M. (Eds). Kardiyak ve Pulmoner Rehabilitasyon. İstanbul, İstanbul Tip Kitabevi. 2014; 365-90.

3. Malik M, Wichterle D, Schmidt G. Heart rate turbulence. G Ital Cardiol 1999;29:65-9. 
4. Schwartz PJ, La Rovere MT, Vanoli E. Autonomic nervous system mechanisms and sudden cardiac death: Experimental basis and clinical observations for post-myocardial infarction risk stratification. Circulation 1992;85(1 Suppl): I77-91.

5. La Rovere MT, Bigger JT Jr, Marcus FI, Mortara A, Schwartz PJ. Baroreflex sensitivity and heart-rate variability in prediction of total cardiac mortality after myocardial infarction. ATRAMI (The Autonomic Tone and Reflexes After Myocardial Infarction) Investigators. Lancet 1998;351:478-84.

6. Lin LY, Lai LP, Lin JL, Du CC, Shau WY, Chan HL, et al. Tight mechanism correlation between heart rate turbulence and baroreflex sensitivity: sequential autonomic blockade analysis. J Cardiovasc Electrophysiol 2002;13:427-31.

7. Priori SG, Aliot E, Blomstrom-Lundqvist C, Bossaert L, Breithardt G, Brugada P, et al. Task Force on Sudden Cardiac Death of the European Society of Cardiology. Eur Heart J 2001;22:1374-450.

8. Watanabe MA, Schmidt G. Heart rate turbulence: a 5-year review. Heart Rhythm 2004;1:732-8.

9. Goel K, Lennon RJ, Tilbury TR, Squires RW, Thomas RJ. Impact of cardiac rehabilitation on mortality and cardiovascular events after percutaneous coronary intervention in the community. Circulation 2011;123:2344-52.

10. Kleiger RE, Miller JP, Bigger JT Jr, Moss AJ. Decreased heart rate variability and its association with increased mortality after acute myocardial infarction. Am J Cardiol 1987;59:256-62.
11. Oliveira NL, Ribeiro F, Teixeira M, Campos L, Alves AJ, Silva G, et al. Effect of 8-week exercise-based cardiac rehabilitation on cardiac autonomic function: A randomized controlled trial in myocardial infarction patients. Am Heart J 2014; 167:753-61.

12. Lampert R, Ickovics JR, Viscoli CJ, Horwitz RI, Lee FA. Effects of propranolol on recovery of heart rate variability following acute myocardial infarction and relation to outcome in Beta-Blocker Heart Attack Trial. Am J Cardiol 2003;91:137-42. 13. Binkley PF, Haas GJ, Starling RC, Nunziata E, Hatton PA, Leier CV, et al. Sustained augmentation of parasympathetic tone with angiotensin-converting enzyme inhibition in patients with congestive heart failure. J Am Coll Cardiol 1993;21:655-61.

14. Mortara A, Specchia G, La Rovere MT, Bigger JT Jr, Marcus FI, Camm JA, et al. Patency of infarct-related artery: effects of restoration of anterograde flow on vagal reflexes. ATRAMI (Automatic Tone and Reflexes After Myocardial Infarction) Investigators. Circulation 1996;93:111-22.

15. Bonnemeier H, Wiegand UKH, Friedlbinder J, Schulenburg S, Hartmann F, Bode F, et al. Reflex cardiac activity in ischemia and reperfusion heart rate turbulence in patients undergoing direct percutaneous coronary intervention for acute myocardial infarction. Circulation 2003;108:958-64.

16. Trzos E, Krzemińska-Pakuła M, Rechciński T, Drozdz J, Kurpesa M. Heart rate turbulence in patients with chronic heart failure. Kardiol Pol 2008;66:1183-90. 